\title{
A Study of Personal Information Management Strategies for Online Faculty
}

\author{
Lorna R. Kearns \\ Barbara A. Frey \\ Christinger Tomer \\ University of Pittsburgh \\ Susan Alman \\ San Jose State University
}

\begin{abstract}
The literature suggests that personal information management is a serious challenge for many computer users. Online faculty are especially challenged because of the large number of electronic files necessitated by teaching online. Those who have experience in this environment may offer valuable insights regarding information management challenges and practices. Faculty who teach online courses as part of the WISE (Web-based Information Science Education) Consortium responded to a survey that questioned the ways they manage e-mail, computer desktops, web-based information, and learning management systems. The authors concluded that "filter failure" rather than information overload is the key issue in information management. The study concludes with a list of recommendations for faculty to manage their personal information.
\end{abstract}

\section{INTRODUCTION}

Dysfunctional information overload has been a clearly identified problem since at least the early 1970s, when Herbert Simon [1] wrote "a wealth of information creates a poverty of attention and a need to allocate that attention efficiently among the overabundance of information sources that might consume it" (p.40). While the problem has been studied within the field of information science, its investigation has not been widely recognized by professionals in other fields who might be impacted by some of its emerging discoveries.

In online education, information overload has been presumed to be a significant factor bearing on the interactions between teachers and students. Information overload is not a subject that has been investigated in any substantial way in regard to its effects or the stratagems employed by teachers or students to cope with the information created by and encountered through participation in an online course. How much information is at issue for online faculty? Precise figures are not available, but it should be noted that in the last installment of the How Much Information [2] surveys, it was reported that the average American consumed about 34 gigabytes on a daily basis. While the growth in the amount of information consumed was expected to continue at relatively modest rates, there was a sense at the time the findings were published that anticipated increases in available bandwidth might have an accelerating effect on the volume of consumption. Since online education tends to be conducted in comparatively high bandwidth settings, it is therefore reasonable to assume that the growth in consumption among both 
students and teachers has been higher than the 3-5\% growth that was projected for the average information consumer.

Most instructors developed their teaching skills by observation and modeling in more or less traditional settings. For most of these instructors, the transition to teaching online came without the benefit of established systems and practices; even teachers with many years of experience have struggled to find effective practices for managing their course-related files. A single online course can easily result in thousands of digital artifacts, and the need to manage those artifacts effectively and efficiently represents a new set of challenges. The purpose of this study was to explore the practices of online faculty in managing the deluge of files associated with their online teaching. The study concludes with a list of recommendations for effectively managing e-mail, computer desktops, and learning management system files.

\section{LITERATURE REVIEW}

\section{A. Personal Information Management}

Personal information management (PIM) comprises all the activities in which individuals engage to "create, store, organize, maintain, retrieve, use, and distribute information" [3, p. 5]. Several studies cited in this section use the term "personal knowledge management" (PKM). Outside of the literature, in ordinary conversation, people sometimes use PIM and PKM interchangeably. Within the literature, some authors make an explicit distinction between the two [e.g., 4, 5, 6, 7]. Benitez and Pauleen imply that PIM is a sub-activity of PKM. In their view, PIM involves finding and storing information. Converting that information into personal knowledge occurs subsequently. Jones and Bruce, however, view personal knowledge as one more type of personal information to be managed. Because this study is an outgrowth of the work of Jones [3] and colleagues, we follow their lead on the meaning of personal information management.

A seminal PIM study was conducted by Jones, Bruce, and Dumais [8], using interviews and observations to collect data from managers, information professionals (like librarians), and researchers about their personal information practices. They proposed three essential domains in need of information management: (1) e-mail, (2) the computer desktop, and (3) web-based information. In a later work, Jones [9] proposes a framework for analyzing PIM activity with three components: (1) "keeping” refers to all the input activities that contribute to creating and maintaining a personal space of information, (2) "finding" refers to how people get things out of their personal space of information, and (3) "M-level activities" are the management activities in which people engage regarding information. Other work by this group of researchers included studies of how PIM strategies vary according to profession [10] and reasons why people abandon PIM strategies [11].

Categories of activities have also been proposed by researchers working within the PKM domain. Razmerita, Kirchner, and Sudzina [7] identified five PKM processes:

1. Knowledge creation

2. Knowledge codification

3. Knowledge sharing

4. Knowledge collaboration

5. Knowledge organization

Avery, Brooks, Brown, Dorsey, and O'Connor [12] proposed a seven-category framework that includes the following:

1. Retrieving information

2. Evaluating information

3. Organizing information

4. Collaborating around information 
5. Analyzing information

6. Presenting information

7. Securing information

Some of the PIM research has focused on individual domains of information management. For example, Whittaker, Matthews, Cerruti, Badenes, and Tang [13] studied personal e-mail practices. On the other hand, an early study by Barreau and Nardi [14] investigated ways in which people organized and searched their computer files. A couple of studies have looked at PIM practices across the multiple domains of email, computer files, and the web [8, 15]. Capra [16] studied how people managed information across multiple electronic devices. Predictably, some authors have made it their goal to describe the desirable features of a desktop PIM tool $[17,18]$.

Some studies have examined the PIM activities of higher education faculty. Douglas [19] conducted interviews with university instructors to learn how they manage digital information for their courses, with a special emphasis on Web 2.0 tools. Kaye et al. [20] interviewed 48 scholars to determine their archiving practices for paper and digital materials. Kaye et al. concluded that while the purpose of the personal archive is to store and retrieve information, it is "more often . . . about other important values, such as building a legacy, sharing information, preserving important objects, and constructing identity" (p. 284). They believed that it is difficult to make recommendations about standardized personal archiving practices because effective practices are those which support a user's idiosyncratic reasons for establishing the archive in the first place.

Finally, several authors argued that PIM practices constitute an important subset of digital literacy, and they made an explicit connection between PIM and the skills needed to participate in e-learning environments [21, 22, 23].

\section{B. Learning Management System Use}

A learning management system (LMS) is "the infrastructure that delivers and manages instructional content, identifies and assesses individual and organizational learning or training goals, tracks the progress towards meeting those goals, and collects and presents data for supervising the learning process of an organization as a whole” [24, p. 28]. The research into the use of LMSs is substantial in volume, but it is not especially powerful in providing insight into how instructors use these systems. Specifically, the existing research does not provide a coherent sense of exactly how teachers and students are using LMSs beyond some obvious uses, such as the delivery of syllabi, reading materials, and announcements or as a medium for discussions and the conduct of examinations. Nor does the research provide a clear sense of how instructors are managing the information that flows into and out of the LMS.

Most of the research regarding LMS usage has been concerned with questions of implementation and acceptance, and, more recently, with efforts to measure attitudes about the LMS among both instructors and students [25]. The findings of these studies indicated that, in many instances, the LMS is used for the management of course materials and information and nothing else. In other instances, the evidence indicated that instructors also use the interactive features of LMSs to promote peer communication and collaboration. However, other studies have raised questions about the extent to which LMSs actually foster connections among students and have provided support for the position that the LMS must be changed and improved substantially so that students can more easily learn from each other and construct new knowledge through their peer interactions [26].

Studies concerned with the perceived benefits of learning management systems suggested that instructors commonly believe LMSs improve communication with students and/or contribute to the efficiency with which courses are delivered, but analyses of how instructors use the tools and other resources embedded in LMSs do not make it clear how these putative benefits are achieved [27]. Only a few studies connected issues of personal information management with the use of learning management systems by instructors, and then only in highly limited terms [e.g., 28]. 


\section{Online Faculty Workload}

The workload associated with online teaching is a concern to both new and experienced faculty members. The 24/7 availability of the Internet sets up an expectation that faculty will be responsive to student questions, discussion postings, and assignments around the clock. In fact, Bolliger and Wasilik [29] identified workload issues as the greatest barrier to faculty participation in online teaching. In their qualitative metasynthesis study, DeGagne and Walters [30] concluded that "online teaching requires more time and effort than face-to-face education” (p. 586). Specifically, Tomei [31] found online teaching demanded $14 \%$ more time than traditional teaching. Sheridan [32] noted that effective workload management begins with the design of a course that is clear, organized, and consistent. He warned that the assessment workload can be particularly demanding. Conceicao and Lehman [33] organized effective workload management strategies into the four categories of design, support, teaching, and time allocation. Ragan and Terheggen [34] also offered workload management strategies in four categories: authoring, teaching, course revision, and institutions. While the literature offered general recommendations to manage the workload of online faculty, few sources provided specific strategies to enhance the management of digital files and information associated with online teaching.

\section{Competencies for Online Teaching}

Identifying and describing competencies for online teaching contributes to the development of effective faculty development programs for online instructors. Virtually all the studies in this body of work identified technology competence and organizational skill as requirements for effective online teaching. An early, often-cited study by Williams [35] identified 13 roles, including those of administrative manager, technology expert, and technician. A competency is a skill required to carry out a task while a role is defined as a collection of competencies. Competencies needed across all roles include technical skills (like basic technology knowledge), technology access knowledge, software skills, and multimedia knowledge as well as managerial skills like organizational skills, project management skills, and personal organization skills.

Another commonly-cited study was conducted by Goodyear, Salmon, Spector, Steeples, and Tickner [36]. This study identified eight roles, including technologist and manager/administrator. Competencies were described in statements like "Understand the capabilities and limitations of the available technologies/platform and infrastructure tools" (p. 71).

Several later studies also identified the roles of technologist and administrator as key. These studies include work by Alvarez, Guasch, and Espasa [37]; Bawane and Spector [38]; Denis, Watland, Pirotte, and Verday [39]; and Varvel [40]. Darabi, Sikorski, and Harvey [41] identified competencies without regard to role. Their list included "manage logistical aspects of course," "use relevant technology effectively," and "accommodate problems with technology" (p. 110). A recent study [42] identified 64 performance statements, an important one being "the instructor uses appropriate strategies to manage the online workload" (p. 68).

\section{E. Research Questions}

A review of the literature, along with anecdotal reports from online instructors, led to the development of the following research questions:

1. What challenges do online instructors face in managing digital information within the areas of email, computer file management, website bookmarks, and learning management systems?

2. What effective practices have instructors used in these areas?

\section{EXPLORATORY STUDY}

An exploratory study was conducted in the summer of 2009 to begin to investigate how online faculty manage digital information associated with their courses. Four online instructors and two instructional designers from several universities participated in two web-based focus groups. Challenges mentioned by 
participants included finding time to keep up with emerging technologies, determining what information to keep track of and what to eliminate, finding previously filed information, and turning older file formats into web-ready documents.

Participants' effective practices for information management were categorized according to the correlating tool context. For e-mail, practices included the creation and ongoing use of folders and e-mail filters and requiring students to include a course name in all messages. Regarding computer desktop practices, folder structure and naming conventions were frequently mentioned. Other practices in this context included converting paper files to digital files, using the desktop Search feature to locate files, and making frequent backups. Web practices mentioned by participants included using social bookmarking sites to share information with students and refraining from downloading items that can be easily accessed online.

Both challenges and effective practices gathered from the focus groups provided input to the development of the survey instrument used for this study.

\section{METHODS}

The evidence provided in the review of the literature made it clear that PIM is problematic for the general population. This research investigates the information management techniques of faculty who are involved in graduate library and information science education and who teach courses in the online environment.

A survey instrument was developed to collect data that focused on the ways in which the faculty experts manage digital assets associated with four types of information tools:

1. E-mail

2. Computer desktop

3. Web-based information

4. Learning management system

A pilot study was conducted among 15 participants to gather preliminary data and to refine the survey instrument. Feedback from the pilot study participants was used to improve the precision of the questions.

Upon receipt of approval by the University of Pittsburgh's Institutional Review Board in the spring of 2011, the researchers contacted the Web-based Information Science Education (WISE) Consortium [43] to obtain the contact information for those individuals who had taught graduate-level online courses in library and information science. The WISE Consortium consists of a group of 15 leading schools in the information field that offer online courses to students enrolled in those schools, thereby increasing the number and variety of online courses available.

In July 2011, a letter of introduction to the project was sent electronically to the 175 instructors who had been identified as former or current instructors in the WISE Consortium. The survey instrument was sent in August 2011. Although the responses of the participants were anonymous, the subjects who completed the survey were afforded an incentive option. Those individuals who completed the survey were invited to send their contact information if they wished to be added to a drawing for a book prize.

\section{RESULTS}

The 65 participants who responded to the survey represent a group of higher education instructors experienced in online teaching in the field of library and information science. Because of their involvement in the WISE Consortium, this group had a considerable number of years of experience in online instruction. Of the group members, $87 \%$ had taught online courses for more than three years, while $50 \%$ had between 6-11 years of online teaching experience. More than six online courses were taught by $66 \%$ of the participants; $42 \%$ had taught more than 11 online courses. The group was $68 \%$ female and $32 \%$ male with $52 \%$ of the group older than 50 years of age.

Chi-square analyses were conducted on the quantitative data to identify relationships between certain patterns of use. Although no significant relationships were discovered within the quantitative data, the 
qualitative data yielded a rich and valuable source of information about PIM practices among this population.

Based on the subject expertise of the group, their significant number of years of online teaching experience, and the high number of online courses taught, the researchers anticipated that participants would reveal highly developed personal information management skills. Yet, as the data were analyzed, it became evident that the participants were experiencing the same frustrations with managing their personal information as the general population.

Results of the qualitative data analysis for each of the information management areas are presented below.

\section{A. E-mail}

As early as 1996, e-mail was identified as one of the most successful computer applications ever devised [44]. Over the past 15 years, there has been a significant increase in the role of e-mail for faculty-student communication. Along with "success" have come a significant number of challenges and personal practices associated with managing e-mail to maintain its effectiveness as a communication and teaching tool for online faculty.

\section{Challenges}

Overwhelmingly, survey respondents identified the volume of incoming messages as their biggest challenge in managing e-mail. As one respondent wrote, "Staying on top of and making decisions (i.e., action needed, no action needed) can be daunting." E-mails included student questions/comments, school/department issues, listserv postings, and other assorted professional obligations. Adding to the volume of messages was the large number of e-mails associated with junk/spam messages, carbon copies from someone else's e-mail conversation, or group message responses using the "reply all" feature, in addition to receiving messages from several e-mail accounts.

Closely related to the volume of e-mails was the time involved in organizing and filing or archiving so many messages. Most faculty tried to maintain a system, but were continuously challenged because "it takes too long to put each e-mail in the right folder." Another faculty member wrote, "The biggest challenge is in prioritizing which e-mails are very important or time-sensitive and keeping up with them during the busiest time of the semester." An instructor who always keeps the e-mail application open wrote, "I work really hard to keep up, otherwise I would fall hopelessly behind. . . . I try to respond pretty much as soon as I get a message." One respondent communicated frustration with the comment, "I gave up trying to archive e-mails due to the time involved."

In addition to the time in reading, responding, and filing messages was the time involved in searching for specific e-mails. A key concern was "findability" or what William Jones [3] referred to as "keeping found things found." An instructor explained, "There are occasions when I KNOW that a message is in the system somewhere, but I can't find it with automatic searching." Filing messages often created an "out of sight out of mind" situation, but a common concern when purging e-mail was reported by the professor who wrote, "I occasionally have deleted e-mails that I wanted to locate."

Several respondents commented on the challenges of the e-mail interface. For example, one instructor wrote, "During the regular semester, I have so many e-mail messages coming in that it is difficult to keep up, especially once they reach the second page of the Gmail interface." Another respondent wrote, "When an e-mail falls 'below the scroll line' I may lose track of it." The limitations of the institution or e-mail provider also presented challenges to users. Five respondents reported problems with limited e-mail storage. A response echoed by several faculty members was, "I'm approaching the limit of my authorized storing space, so I have to do a major cleaning. I find that making the decision that I'm not likely to need an e-mail in the future requires extra time that I don't have.”

While most survey responses focused on the deluge of e-mails and the challenges of managing hundreds or thousands of messages, there were three survey responders who did not find managing e-mail to be challenging. One instructor wrote, "I've been using email since 1992 when it was run by magic, and in 20 years I've learned to manage e-mail very well.” Another respondent prevented e-mails from becoming a 
challenge by checking for messages on a daily basis. However, these satisfied instructors were in the minority.

\section{Effective Practices}

Out of necessity, the online instructors developed a wide variety of effective personal e-mail management strategies. Diligently deleting e-mails was a basic practice that prevented the amount of messages from becoming overwhelming. When it was necessary to keep the e-mails, creating folders was the most effective practice reported by respondents, with 50\% reporting using some system of folders and subfolders. One person reported, "I don't keep important documents in my e-mail system-I file them in the proper folder.” This was part of the handle-it-once strategy to respond, delete, flag, or file incoming messages. A respondent described that using the same file structure on both work and home computers was an effective practice. Furthermore, several people emphasized the importance of "records management," such as maintaining an effective filing system by regular "weeding" or purging of useless folders. However, not everyone used digital files and folders-one respondent reported using a small notebook "to physically record e-mail messages that require action" and periodically printing key e-mails to file as hard copies.

There was less agreement in how to keep up with the daily deluge of e-mails. Some instructors had an approach of staying on top of messages and dealing with them as quickly as possible, and others only checked e-mail once or twice per day. For example, one faculty member found it effective to "try to deal with it right away." Another instructor using a similar philosophy wrote, "I use my iPhone for quick response time and follow up with my PC for depth." Another respondent had the opposite approach and wrote, "I don't open messages unless the subject line makes it clear that it needs immediate action."

One instructor used several e-mail accounts with different purposes, but admitted it was challenging to get people to send messages to the correct e-mail account. Two respondents recommended communicating clear online teaching expectations that include how to contact the instructor and the instructor's standard response times (e.g., 24-48 hours). One instructor wrote that action items sometimes become a problem and marked e-mails "as unread and pretends they just arrived the next day." Several instructors used a system of tagging or flagging to indicate action items. Finding the best practices is a work in progress for a respondent who wrote, "Still working on it."

\section{B. Computer Desktop}

In addition to e-mail, faculty must keep track of a large number of text and multimedia files on their personal computers. These files can include course content, assignment instructions, resource materials, and of course, student assignments.

\section{Challenges}

The most commonly mentioned challenge involved with managing computer files was volume. As one respondent put it, "The main challenge is how to deal with a large and ever increasing number of files," suggesting that a filing system that might have worked in the past simply could not address the volume of the present. For some respondents, the issue is time: e.g., "I don't file them nearly often enough," and "I don't have time to go in and sort them out." Other respondents were thwarted in their efforts to implement an effective filing system. One respondent identified the biggest challenge as "how to name them with all the info I need to recognize what is in them.”

Several respondents recommended consistency in naming files and folders. As volume increases over time, however, threats to consistency do as well: "Many years of accretion make it difficult to maintain consistency over time," was one response in addition to "Even though I have a good organizational schema and naming convention, I can't always remember what a file is called or where I put it. In the short term, it's not a problem but over the longer term (more than a year or so), I forget.” Additionally, versioning presents specific problems. As one respondent stated, "I cannot effectively manage several projects' files and their many versions or updates.” 
Several people mentioned needing better file backup practices. Most of those who mentioned backups implied what one user stated outright: "I don't back up nearly as often as I should.” Finally, for some people, challenges resulted from maintaining files across different devices. One respondent reported difficulty in "coordinating between computers, online platform, flash drives, etc." Another stated that challenges resulted from "not being able to sync easily folders between a mac and a pc [sic].”

\section{Effective Practices}

In response to the question about effective practices for computer file management, 19 out of 63 people described an effective practice, the most common being the use of folders and naming conventions. As one respondent said, "Folder and file naming conventions are key." Echoing a theme that appeared in answer to the question about challenges, several people reiterated the importance of consistency. One person said, "Everything is structured in a taxonomy of folders and subfolders and I have used the same labels for many years," while another simply urged, "Be consistent!"

When asked in an earlier question how they search for files on their computers, slightly more than $80 \%$ of respondents said they search for files where they assume they will find them. Many of the specific organization and naming practices people described contribute to a strategy in which "discovery is intuitive." More than one respondent reported using course numbers in file names. One person mentioned an "attempt to use naming conventions that include versioning and dates," while another uses "a consistent classification system . . . that readily communicates to me what the information object(s) is/are."

File backup was another area that people believed was important for effective practice. While multiple respondents endorsed frequent backups, there was some divergence as to the best way to achieve a proper backup system. While one person mentioned a tendency "to save files to more than one place, e.g. Desktop folders, Documents, and flash drives," another said, "I've stopped saving files to different computers and started saving only to flash drives or Google Docs.” This divergence suggests that tension exists between ensuring some file redundancy for security purposes and navigating among different operating systems and computing devices, especially in regard to file versioning.

A final theme that emerged among the descriptions of effective practices was the use of web-based thirdparty applications. For file backup, people mentioned fee-based Mozy software as well as Syncback, an application that has both a fee-based and a free version. Dropbox is a free, file storage application that people use to access files from multiple devices and to share documents with colleagues and students. Finally, Google Drive (formerly Google Docs) was mentioned as a tool that supports both file storage and file sharing.

\section{Web-based Information}

The massive amount of information on the World Wide Web offers both opportunities and challenges to faculty - the opportunity to provide valuable resources to supplement teaching and the challenge to organize those resources in a useful format.

\section{Challenges}

The survey queried participants on how they kept track of information gathered from the web to use at later dates. The majority of participants reported that there is too much web-based information to manage or to remember. As one respondent said, "The biggest challenge is figuring out a strategy to begin with. Right now it's hit or miss." Another complained about "overload and disorganization” while another reported that "I have different bookmarks saved on the toolbars of my different computers."

Specific problems resulted for some participants from the use of passwords to gain access to multiple websites. As one respondent said, "Passwords ... grrr." Another respondent alluded to the ephemeral nature of web-based information: "Information being deleted from the web-many site managers do not appreciate the importance of long term preservation.” A general note of resignation can be heard in the remark, "Sometimes I just hope that I'll remember the website." 


\section{Effective Practices}

Despite the challenges, the overwhelming majority of the respondents $(70 \%)$ reported that they managed web-based information through the bookmark function in web browsers. Later in the analysis, the respondents indicated that this method was problematic due to the volume of sites and the lack of an organizational scheme. Those respondents who used the bookmarking function on their browser reported limited use of bookmark folders. While $62 \%$ reported the use of folders for their bookmarked items, the majority (60\%) used 10 or fewer folders. These folders were created and named for courses they taught, and in two instances, the bookmark folders were named for course assignments.

The participants reported that they created bookmark folders for each course that is taught, for gathering information on a new topic, or when breaking a broad topic into subcategories. Bookmarks are deleted when the information is no longer relevant or the links are broken. Ten percent of respondents reported that they never delete a bookmark.

Other mechanisms that were used by some participants to save web-based information included the following:

- Social bookmarking sites like Delicious (23\%)

- Saving URLs to a Word document (23\%)

- Saving copies of HTML pages on computer (14\%)

- Saving content from HTML pages to a Word document (18\%)

- $\quad$ Saving content from HTML pages to a PDF file (23\%)

- Sending URLs in an e-mail message to themselves (42\%)

There was a $26 \%$ rate of response when participants were asked about the web-based information practices they would recommend. Nearly half of those who responded reported that they did not have any best practices to share; a much higher rate of response was anticipated based on the expertise of the group.

Reported best practices fell into the general categories of using information immediately before forgetting and developing a structured bookmarking system. Some of the specific suggestions included using Zotero for bibliographic management, which was noted as being "vigilant in keeping as few sites bookmarked as possible"; saving websites to a smartphone with "each one [website] showing up as an icon under the web function"; and using "RSS readers in the bookmarks (in my toolbox) on Firefox to keep up with new information, posts, etc.”

\section{Learning Management Systems}

The segment of this investigation concerned with learning management systems revealed, surprisingly, that slightly less than half of the respondents did not use the learning management system (LMS) available to them; 15\% professed not to know whether or not they were using an LMS. This latter finding is puzzling, but it may be yet another indication that in many places, the extent to which instructors are prepared for online instruction is so limited and so ineffectual that they often lack knowledge of even the most basic terminology.

\section{Challenges}

Responses to questions about the use of web-based applications mounted outside the framework of the LMS divided the respondents into groups of almost equal size, with $48 \%$ indicating that they used external applications, including audio, video, blogs, wikis, games, social bookmarking services, chat applications, VOIP services, Twitter, and cloud-based collaboration and/or document sharing services. Of the instructors that did use externally mounted web applications, almost 25\% used Google Docs, 20\% used wikis, and $16 \%$ used blogs.

The precise meaning of these results is difficult to characterize, but it does suggest that the dissatisfaction with the LMS as a medium for interaction with students is considerable. The findings also suggest that 
instructors with serious misgivings about the LMS as an environment for online instruction are divided in terms of what external application or set of applications constitutes an effective remedy to the perceived limits of the LMS.

When asked to identify the most important issues that they confronted in using an LMS, two-thirds of the respondents cited what may be classified as design issues. In some instances, the complaints cited a specific feature of the system in use, but in most cases the respondents were articulating a more general conviction that the LMS could be and should be a more efficient and more effective instrument. As one respondent said, "Never seems to have the tools I need integrated in a way that I need them integrated." Several respondents also mentioned difficulties stemming from LMS version upgrades.

\section{Effective Practices}

The majority of respondents use their own personal computing environment to augment both the storage capacity and authoring functionality of their LMS. Regarding the authoring process, one respondent mentioned that "better editing tools" were available on the personal computer than the LMS. On the issue of storage, one respondent explained that "with migrations from Blackboard to Angel to D2L over a 4year period, this has been useful and necessary." Others commented on the need to access course materials in the event that the LMS or Internet was not available.

As mentioned in the context of other tools, several respondents remarked that consistency was an important factor in effectively using the LMS. Participants who advocated for consistency believed that it benefits students as well as themselves. As one respondent said, "I have consistent ways of naming my files, which helps me and students to keep track of them.” Another said, "Consistently naming items and providing way-finding information on my [LMS] are vital process steps for me as the instructor, as well as my students and Teaching Assistants working with me.”

\section{E. Cross-context}

Questions at the end of the survey asked participants to comment on challenges they encountered and practices they used to manage and coordinate information across all four of the tool contexts (e-mail, computer desktop, web, and LMS).

\section{Challenges}

Cross-context challenges and practices are those associated with managing related information across email, computer desktop, web, and LMS contexts. An example would be an e-mail from a student about an assignment that the instructor has downloaded from a specific area of the LMS and stores in a particular folder on his/her computer desktop.

The survey did not ask an open-ended question about cross-context challenges. Rather, it asked instructors to specify how frequently they found the management of cross-context information to be difficult. Eighty-six percent of the respondents reported experiencing some level of difficulty.

\section{Effective Practices}

About $40 \%$ of the instructors responded to the open-ended question about effective practices for managing information across contexts, although some responses were without suggestion, such as "I have not devised any practices that I feel are particularly innovative," or the stoic "I slog on and upward, ever reaching for the (seemingly) unattainable goal of organization.”

A majority of responses mentioned naming conventions and consistency as key elements of effective practice, although the language used in some of the remarks ("try to use naming conventions," "try to be more consistent") implies that while instructors believe these elements to be important hallmarks of practice, instructors are not always successful at incorporating them. Competing demands on time seem to be a significant impediment. As one instructor put it, "I try to be consistent, but sometimes I'm in a rush and that doesn't happen.” For some, the answer is to process items as they come in. One instructor advocated "actively managing information objects as they are received and created" and being "careful to 
create the organizational scheme ahead of time." Another instructor recommended "taking time to rename, reorganize, and rearrange to keep consistent.”

A few respondents mentioned the potential of cloud computing to offset some of the challenges on managing cross-context information. For one instructor, the cloud provided the ultimate solution: "Using the cloud for a lot of the course-work and hosting means that a lot of the time these management issues don't come into play." Another instructor, however, still had some reservations: "I am intrigued by the opportunities that cloud computing may present for managing information across contexts and platforms. However, I have some significant privacy and longevity concerns about cloud computing.”

Managing information across contexts entails all the challenges of managing within individual contexts. It is a complicated task, the solution to which often involves multiple tools and strategies. The remarks of the instructor quoted below convey the complexity of the problem and exemplify just one of multiple paths that might be taken in response to information management:

The challenge of managing information across contexts plagued the early years of my teaching. I had trouble with version control and missing documents. Only when I figured out how to use a uniform file structure across computers, developed a course structure in [my institution's LMS] that works, use [my institution's LMS] as the central repository for all of my course materials, resigned myself to the fact that updating my course materials with course management software is much more time consuming than doing it the old-fashioned way, adopted Zotero in conjunction with a separate file for reading and resources for each course I teach, and have effective backups, did it become at least livable.

\section{RECOMMENDATIONS}

Based on input from the respondents regarding effective practices synthesized with the PIM literature, a number of suggestions can be made for online faculty wishing to experiment with strategies for managing personal information associated with online teaching.

\section{A. E-mail}

In most professional environments, e-mail has replaced postal mail and telephone calls. The substantial volume and varied nature of e-mail messages create challenges beyond a simple organizational filing structure. The information communicated through e-mail has many purposes, media, writing styles, lengths, attachments, senders/receivers, and other unique qualities. The following recommendations are based on the information management literature and practices identified by the faculty survey respondents.

\section{Sending}

- The subject line serves as an advanced organizer for the receipt of your message. Always use the subject line and make effective use of the line to describe your purpose. It is often more effective to send two short e-mail messages with different subject lines than one long message with a generic subject line.

- If replying to a chain of e-mail messages, consider changing the subject line to reflect the new information you added to the ongoing dialogue. Modifying the subject line makes it easier to find information in the chain of communication.

- The "To" field in e-mail should contain the e-mail address of the person you expect to reply to the message. The "CC" field is used only for those people who need to know what is being communicated; this field should be used sparingly, as should the "Reply to all" response option.

- Write short, succinct messages in full sentences and paragraph format. Make your most important point first. Consider whether your communication would be more effective in an attached document than in the body of an e-mail message. 


\section{Receiving}

- Deal with e-mails efficiently with a triage strategy of read, delete, act, flag, or file the messages. Ideally, your inbox should only include e-mails that require action.

- Develop a consistent filing system similar to the system you use for computer desktop files.

- For critically important e-mails that you will have to retrieve, consider filing them to several folders.

- If you don't have time to deal with a message, mark it as "unread" to postpone (but not forget) the message.

- Use filters to direct regular e-mails to specific folders based on course, sender, or listserv name.

- Provide students with specific instructions for sending e-mail messages, such as using the course name (e.g., "EDUC 554”) in the subject line and signing both first and last name to messages.

- Provide a General Questions discussion forum in your online courses. Direct students to post questions of interest to all students in this area and check it frequently. Some faculty encourage students who know the answer to a classmate's question to respond.

- Manage student expectations for e-mail response times by including this information in your course syllabi. In general, faculty response times for personal e-mails vary from 24 to 72 hours.

- Require students to submit assignment files via the course management system rather than e-mail.

- Even with the best of e-mail practices, you will likely need to periodically devote time to cleaning and filing your inbox messages.

\section{B. Computer Desktop}

A comment made repeatedly by study participants in regard to computer desktop practices was the notion of a consistent folder structure and naming system to keep files organized and retrievable. Those participants who used such a system considered the time and energy needed to create and maintain it a worthwhile investment of resources.

- Create folders for each course you teach. Within each folder, create sub-folders for different semesters.

- Use file names that effectively describe the contents of the file to enable intuitive discovery.

- If you cannot remember where you filed something, use your computer operating system's Search function.

- Develop a convention for version identification (e.g., filename_v1, filename_v2) and include it in file names.

- Instruct students to follow a file naming convention for submitted assignments. Upon receipt, rename submissions that do not conform.

- Once you have established an organization and naming convention that works, use it consistently.

- Develop and adhere to good backup practices. Consult the technology support resources at your institution for advice on establishing an effective system.

- Explore the possibility of using a web-based cloud service for backup, but be aware of the risks to privacy and longevity of data.

\section{Web-based Information}

Managing web-based information can be especially challenging due to multiple formats, massively distributed locations, and sheer volume. Respondents from this survey who reported effective practices made use of cloud-based applications for collecting and organizing web resources. 
- Develop a structured bookmarking system. Explore the possibility of using a web-based system like Delicious in order to access bookmarks from different devices.

- Subscribe to Really Simple Syndication (RSS) readers to keep current with relevant and timely information.

- Utilize a web-based reference management system like Zotero as a way to store and organize bibliographic references.

\section{Learning Management System}

Learning management systems (LMSs) provide many benefits to both faculty and students. Indeed, it is difficult to imagine how instructors could effectively conduct an online course without one. Still, the current LMS landscape is not without limitations. Effective practices tend to focus on ways to overcome these limitations.

- Keep backup copies of course files on your personal computer. Download and keep copies of student work on your personal computer.

- Use document processing software like Microsoft Word to take advantage of the software's enhanced editing functions while retaining a local copy of your work before you post to the LMS.

- Participate in training opportunities to learn more about the functionality of the LMS in use at your institution.

\section{E. Cross-context}

An important recommendation for managing information across contexts is to create an organizing framework that uses the same structure and naming conventions for e-mails, computer files, and web bookmarks. This approach promotes continued adherence to the conventions established by the instructor and may offset the constant pull of entropy mentioned so often by survey respondents.

- Align file and folder names and organizational structure across e-mail, your computer desktop, and web bookmarks.

- Use web-based cloud storage to access files across devices but, as with cloud backups, be aware of the risks.

\section{CONCLUSION}

It has been suggested that information overload is one of the foremost challenges of the contemporary Internet and also that information overload may be dealt with effectively through the imposition of algorithmic filtering mechanisms. Or, as Clay Shirky has controversially argued, "it's not information overload. It's filter failure" [45]. While Shirky is concerned with more global aspects of this issue, his ideas about managing information also characterize the plight of online instructors, who are compelled to deal with high volumes of information but typically lack the wherewithal to manage the flow of this information on an automatic or systematic basis. The findings of this study strongly corroborate this point of view, and do so in reference to several different aspects of online teaching, including the management of electronic mail, computer files and folders relating to instruction, and web-based information resources, as well as the organization of these data across contexts, platforms, and devices.

It is clear that many online faculty are unaware of the wide variety of tools and techniques available to develop an individualized, personally relevant PIM strategy. Therefore, it is advisable that institutional faculty development efforts address this need and incorporate the introduction of such tools and techniques into existing development programs. Moreover, consideration should be given to creating new programs specifically designed to familiarize faculty with PIM issues and solutions. Faculty should be encouraged to explore and experiment not only with technologies, but also methods and approaches for organizing and retrieving information. 
Notwithstanding the recommendations made in the previous section, it should also be noted that an individual PIM strategy is a highly personal and idiosyncratic matter consisting of processes that work together within a particular ecology of needs and affordances. A set of techniques that work well for an undergraduate math instructor may be inappropriate for a marketing professor teaching in an MBA program. A tool that perfectly addresses the needs of one person may not "feel right" to another. Kaye et al. [20] insist that a personal space of information is maintained not only to facilitate PIM, but also to serve personal values such as "building a legacy, sharing information, preserving important objects, and constructing identity" (p. 284). Therefore, the recommendations made in this paper should be taken as starting points, not prescriptions for achieving an ideal strategy. It is hoped that online faculty will experiment with those methods that hold personal promise; however, faculty are encouraged to refine, combine, or even abandon methods as needed.

It is recommended that researchers with an interest in LMSs focus on achieving a better understanding of how online instructors interact with students in order to assess how an LMS meets these interaction requirements. In addition, it would be helpful to pursue a more precise understanding of the tradeoffs obtain when an instructor uses externally mounted resources, such as blogs, wikis, and third-party content management systems, for the purpose of conducting class activities.

The results of this study suggest that instructors commonly have problems linking the LMS to their computer desktops and these problems might be ameliorated if the relationship between the LMS and the instructor's desktop could be rendered simpler and more direct. It seems reasonable to propose that efforts should be made to develop and test software applications that link course shells on LMSs with computer desktops and allow common desktop applications to write directly to the file system underlying the LMS. In the past, the proprietary nature of productivity software was a major impediment to building such linkages. Today, however, thanks to open technical standards, these impediments have been removed. It is now far more realistic to imagine a version of OpenOffice that can be configured to interoperate directly with a variety of proprietary and open source LMSs.

There are some who will argue that it is unrealistic to expect that learning management systems will be available in the near future that are capable of automating the management of data and the creation of the metadata necessary for its retrieval. There are others who believe that the transformation of the LMS has already begun, and the next generation of learning management systems "will adapt to the art of teaching as opposed to faculty having to adapt to a particular technology" [46, p. 50].

Will such systems remove the personal information management problems that appear, by the reckonings of this study, to be a common and highly counterproductive element of online teaching? There is reason for optimism, but in view of the findings of this study, perhaps the safest stance is to propose that solving the personal information management problems of online instructors is a challenge of the first order for the future of online education.

\section{REFERENCES}

1. Simon, H.A. Designing Organizations for an Information-rich World. In: Greenberger, M. (Ed.), Computers, Communications, and the Public Interest, The Johns Hopkins University Press: Baltimore, MD, 37-72, 1971.

2. Bohn, R.E. and Short, J.E. How Much Information? 2009 Report on American Consumers. Global Information Industry Center, University of California, San Diego, 2009. http://hmi.ucsd.edu/pdf/HMI_2009_ConsumerReport_Dec9_2009.pdf.

3. Jones, W. Keeping Found Things Found: The Study and Practice of Personal Information Management, Morgan Kaufmann: San Francisco, CA, 2007.

4. Benitez, E.A. and Pauleen, D. Brainfiltering: The Missing Link between PKM and PIM? Proceedings of the Americas Conference on Information Systems 2009 (2009). http://aisel.aisnet.org/amcis2009/13/. 
5. Cheong, R.K.F. and Tsui, E. The Roles and Values of Personal Knowledge Management: An Exploratory Study. Journal of Information and Knowledge Management Systems, 40(2): 204-227 (2010).

6. Jones, W. and Bruce, H. A Report on the NSF-sponsored Workshop on Personal Information Management. The Information School, University of Washington, Seattle, WA, 2005. http://pim.ischool.washington.edu/final\%20PIM\%20report.pdf.

7. Razmerita, L., Kirchner, K., and Sudzina, F. Personal Knowledge Management: The Role of Web 2.0 Tools for Managing Knowledge at Individual and Organisational Levels. Online Information Review, 33(6): 1021-1039 (2009).

8. Jones, W., Bruce, H., and Dumais, S. Keeping Found Things Found on the Web. Proceedings of the Tenth International Conference on Information and Knowledge Management, 119-126 (2001). http://research.microsoft.com/en-us/um/people/sdumais/cikm paper camera-ready.pdf.

9. Jones, W. Personal Information Management. In Cronin, B. (Ed.), Annual Review of Information Science and Technology (Book 41), Information Today Inc.: New Medford, NJ453-504, 2007.

10. Bruce, H., Jones, W., and Dumais, S. Keeping and Re-finding Information on the Web: What Do People Do and What Do They Need? Proceedings of the American Society for Information Science and Technology, $41 \quad$ (2004). $\quad$ http://adammikeal.org/courses/ht/files/readings/refinding information on the web3.pdf.

11. Jones, E, Bruce, H., Klasnja, P., and Jones, W. I Give Up! Five Factors that Contribute to the Abandonment of Information Management Strategies. Proceedings of the American Society for Information Science and Technology, 45 (2008). http://kftf.ischool.washington.edu/rerecentpublicationaboutplanner/Jones,\%20E,\%20et\%20al,\%202 008,\%20I\%20give\%20up.pdf.

12. Avery, S., Brooks, R., Brown, J., Dorsey, P., and O’Conner, M. Personal Knowledge Management: Framework for Integration and Partnerships. Proceedings of the 2001 ASCUE Summer Conference: 28-39 (2001). (ERIC Document Reproduction Service No. ED 456 814).

13. Whittaker, S., Matthews, T., Cerruti, J., Badenes, H., and Tang, J. Am I Wasting My Time Organizing Email? A Study of Email Refinding. Proceedings of CHI 2011 (2011).

14. Barreau, D. and Nardi, B. Finding and Reminding: File Organization from the Desktop. SIGCHI Bulletin, 27(3) (1995). http://old.sigchi.org/bulletin/1995.3/barreau.html.

15. Boardman, R. and Sasse, M.A. "Stuff Goes into the Computer and Doesn't Come Out”: A Crosstool Study of Personal Information Management. In: Proceedings of CHI 2004, ACM: New York, NY, 583-590, 2004.

16. Capra, R. A Survey of Personal Information Practices. Paper presented at the Personal Information Management ASIS\&T 2009 Workshop, November 7-8, 2009: Vancouver, BC, Canada, 2009. http://www.pimworkshop.org/2009/papers/capra-pim2009.pdf.

17. Chirita, P. Organization and Usage of Learning Objects within Personal Computers. Deliverable of the European Commission Sixth Framework Project, 2006. http://hal.inria.fr/docs/00/58/88/11/PDF/Chirita-Prolearn-2006.pdf.

18. Edmonds, G.S. and Pusch, R. Creating Shared Knowledge: Instructional Knowledge Management $\begin{array}{lllll}\text { Systems. } \quad \text { Educational Technology and } & \text { Society, }\end{array}$ (2002). http://www.ifets.info/journals/5_1/edmonds.pdf.

19. Douglas, I. An Ethnographic Study of Individual Learning Content Management. 9th IFIP World Conference on Computers in Education (WCCE 2009): Bento Gonçalves, Brazil, 100-105.

20. Kaye, J., Vertesi, J., Avery, S., Dafoe, A., David, S., Onaga, L., Rosero, I., and Pinch, T. To Have and to Hold: Exploring the Personal Archive. Proceedings of CHI 2006, 275-284 (2006).

21. Li, W. and Liu, Y. Personal Knowledge Management in E-learning Era. In: Technologies for Elearning and Digital Entertainment, Lecture Notes in Computer Science, Vol. 5093, Springer Berlin Heidelberg: 200-205, 2008. 
22. Pettenati, M. C. and Cigognini, M.E. Designing E-tivities to Increase Learning-to-learn Abilities. Elearning Papers, 12 (2009). http://www.elearningeuropa.info/files/media/media18509.pdf.

23. Tsui, E. Technologies for Personal and Peer-to-peer (P2P) Knowledge Management. CSC Leading Edge Forum (LEF) Technology Grant Report (2002). http://go.webassistant.com/wa/upload/users/u1000057/p2p_km.pdf.

24. Watson, W.R. and Watson, S.L. An Argument for Clarity: What Are Learning Management Systems, What Are They Not, and What Should They Become? TechTrends 51(2): 28-34 (2007).

25. McGill, T.J. and Klobas, J.E. A Task-technology Fit View of Learning Management System Impact. Computers and Education, 52(2): 496-508 (2009).

26. Lonn, S. Student Use of a Learning Management System for Group Projects: A Case Study Investigating Interaction, Collaboration, and Knowledge Construction. Doctoral dissertation retrieved from ProQuest Dissertations and Theses (3392847) (2009).

27. Lonn, S. and Teasley, S.D. Saving Time or Innovating Practice: Investigating Perceptions and Uses of Learning Management Systems. Computers and Education, 53(3): 686-694 (2009).

28. Hershkovitz, A., Azran, R., Hardoff-Jaffe, S., and Nachmias, R. Types of Online Hierarchical Repository Structures. Internet and Higher Education, 14(2): 107-112 (2011).

29. Bolliger, D.L. and Wasilik, O. Factors Influencing Faculty Satisfaction with Online Teaching and Learning in Higher Education. Distance Education, 30(1): 103-116 (2009).

30. DeGagne, J.C. and Walters, K. Online Teaching Experience: A Qualitative Metasynthesis. MERLOT Journal of Online Learning and Teaching, 5(4): 577-589 (2009). http://jolt.merlot.org/vol5no4/degagne_1209.pdf.

31. Tomei, L.A. The Impact of Online Teaching on Faculty Load: Computing the Ideal Class Size for Online Courses. Journal of Technology and Teacher Education, 14(3): 531-541 (2006).

32. Sheridan, R. Reducing the Online Instructor's Workload. Educause Quarterly, 3, 65-67 (November 2006). http://www.educause.edu/ero/article/reducing-online-instructor\%E2\%80\%99s-workload.

33. Conceicao, S.C.O. and Lehman, R.M. Faculty Strategies for Balancing Workload when Teaching Online. Midwest Research-to-Practice Conference in Adult, Continuing, Community, and Extension Education, Michigan State University: East Lansing, MI, September 2010. https://www.msu.edu/ mwr2p/ConceicaoLehman-MR2P-2010.pdf.

34. Ragan, L.C. and Terheggen, S.L. Effective Workload Management Strategies for the Online Environment. Report funded by a Grant from The Alfred P. Sloan Foundation to Pennsylvania State University World Campus, 2003. http://www.worldcampus.psu.edu/pdf/fac/workload strat.pdf.

35. Williams, P. Roles and Competencies for Distance Education Programs in Higher Education Institutions. American Journal of Distance Education, 17(1): 45-57 (2003).

36. Goodyear, P., Salmon, G., Spector, J.M., Steeples, C., and Tickner, S. Competences for Online Teaching: A Special Report. Educational Technology Research and Development, 49(1): 65-72 (2001).

37. Alvarez, I., Guasch, T., and Espasa, A. University Teacher Roles and Competencies in Online Learning Environments: A Theoretical Analysis of Teaching and Learning Practices. European Journal of Teacher Education, 32(3): 321-336 (2009).

38. Bawane, J. and Spector, J.M. Prioritization of Online Instructor Roles: Implications for Competency-based Teacher Education Programs. Distance Education, 30(3): 383-397 (2009).

39. Denis, B., Watland, P., Pirotte, S., and Verday, N. Roles and Competencies of the E-tutor. Proceedings of the Networked Learning Conference 2004 (2004). http://www.networkedlearningconference.org.uk/past/nlc2004/proceedings/symposia/sympo sium6/denis_et_al.htm.

40. Varvel, V. Master Online Teacher Competencies. Online Journal of Distance Learning Administration, 10(1) (2007). http://www.westga.edu/ distance/ojdla/spring101/varvel101.htm.

41. Darabi, A.A., Sikorski, E.G., and Harvey, R.B. Validated Competencies for Distance Teaching. Distance Education, 27(1): 105-122 (2006). 
42. Bigatel, P.M., Ragan, L.C., Kennan, S., May, J., and Redmond, B.F. The Identification of Competencies for Online Teaching Success. Journal of Asynchronous Learning Networks, 16(1), 59-78 (2012).

43. WISE. Web-based Information Science Education. http://www.wiseeducation.org/.

44. Whittaker, S. and Sidner, C. Email Overload: Exploring Personal Information Management of Email. In: Proceedings of CHI'96 Conference on Computer Human Interaction, ACM Press: New York, NY, 276-283, 1996.

45. Shirky, C. It's Not Information Overload. It's Filter Failure. Web 2.0 Expo, 2008. http://www.web2expo.com/webexny2008/public/schedule/detail/4817.

46. Pugliese, L. A Post-LMS World. Educause Review, 47(1): 50-51 (2012). http://www.educause.edu/ero/article/post-lms-world.

\section{ACKNOWLEDGEMENTS}

The authors are grateful to the WISE Consortium and the members of the WISE faculty for their participation in this study.

\section{ABOUT THE AUTHORS}

Lorna R. Kearns is Director of Online Programs in the Center for Instructional Development and Distance Education at the University of Pittsburgh. She holds a master's degree in Information Science from the University of Pittsburgh and is completing her Ph.D. in Adult Education at the Pennsylvania State University. Her research interests include accessible course design for online courses and the faculty experience in online teaching.

Barbara A. Frey, D.Ed., is a senior instructional designer with Pitt Online at the University of Pittsburgh. In addition, Dr. Frey teaches with the Online Teaching and Learning Program at Colorado State University's Global Campus. She is also a master reviewer and trainer with Quality Matters.

Christinger Tomer is an associate professor at the University of Pittsburgh and partner in FastTrack Associates. His areas of specialization include digital media, online teaching and learning, and library and archival computing. He is a graduate of the College of Wooster and Case Western Reserve University.

Susan Alman, Ph.D., is a faculty member in the School of Library and Information Science at San Jose State University. Her teaching and research areas include online education, interpersonal communication, management/marketing, and faculty development. Dr. Alman is a graduate of Washington and Jefferson College and the University of Pittsburgh. 